\title{
Melt Viscosity of the Soft Magnetic Nanocrystalline $\mathrm{Fe}_{72.5} \mathrm{Cu}_{1} \mathrm{Nb}_{2} \mathrm{Mo}_{1.5} \mathrm{Si}_{14} \mathrm{~B}_{9}$ Alloy
}

\author{
Vladmir Tsepelev ${ }^{1, *}$, Yuri Starodubtsev ${ }^{1,2}$, and Victor Konashkov ${ }^{1}$ \\ ${ }^{1}$ Boris Yeltzin Ural Federal University, Ekaterinburg, Russia \\ ${ }^{2}$ Gammamet Research and Production Enterprise, Ekaterinburg, Russia
}

\begin{abstract}
Temperature dependences of the kinematic viscosity of a multicomponent $\mathrm{Fe}_{72.5} \mathrm{Cu}_{1} \mathrm{Nb}_{2} \mathrm{Mo}_{1.5} \mathrm{Si}_{14} \mathrm{~B}_{9}$ melt have been studied. A critical temperature is detected above which the activation energy of the melt' viscous flow changes. Comparison of the temperature dependences of the kinematic viscosity of the melts prepared from the initial ingot and an amorphous ribbon shows that the melt viscosity essentially depends on the initial structural state of the alloy. In amorphous ribbon produced in the mode with overheating, and the melt is above the critical temperature, the enthalpy of crystallization grows; the following heat treatment results in an increase in magnetic permeability.
\end{abstract}

\section{Introduction}

Soft magnetic nanocrystalline materials are distinguished by low coercivity and high magnetic permeability magnitudes which are provided by a nanocrystalline, structure [1]. The fabrication of these materials includes three stages. At the first stage, an alloy of a given composition is melted. Then, using ultrarapid quenching, an amorphous metallic ribbon of about $25 \mu \mathrm{m}$ thickness is produced. At the third stage, in the course of heat treatment, an optimum nanocrystalline structure is formed in the ribbon.

The effect of temperature in preparing the melt before casting, which is aimed at creating an amorphous structure in iron-based alloys, was investigated in a number of works [2-6]. It was shown that with increasing the temperature of the melt before casting the ribbon becomes more plastic, its electrical resistance and crystallization temperature grow, and its density lowers. On the other hand, the increased temperature of the melt deteriorates the quality of the ribbon surface and efficiency of its production. Therefore, it is important to find an optimum mode of preparing the melt before casting. As a characteristic feature of a multicomponent melt, a critical temperature $T_{k}$ can be specified [6], above which the properties of the melt irreversibly change upon cooling. Irreversibility manifests itself in a hysteresis of kinematic viscosity, surface tension, and other properties of the melt. The hysteresis can arise as a result of breaking interatomic bonds which control the short-range order in the melt.

In the paper, the results of measurements of the $\mathrm{Fe}_{72.5} \mathrm{Cu}_{1} \mathrm{Nb}_{2} \mathrm{Mo}_{1.5} \mathrm{Si}_{14} \mathrm{~B}_{9}$ melt viscosity are presented. Using different models of a liquid state, the temperature dependences of

\footnotetext{
* Corresponding author: v.s.tsepelev@urfu.ru
} 
kinematic viscosity are constructed, which allow us to determine the critical temperature for the nanocrystalline alloy. The parameters of the crystallization process and magnetic properties of ribbons produced after different modes of the melt preparation before casting are investigated.

\section{Experimental}

Alloys of the $\mathrm{Fe}_{72,5} \mathrm{Cu}_{1} \mathrm{Nb}_{2} \mathrm{Mo}_{1,5} \mathrm{Si}_{14} \mathrm{~B}_{9}$ composition were melt in a vacuum induction furnace. Kinematic viscosity of the melts is measured by the torsional vibration method based on measuring the vibration damping factor [7]. The measurement error of kinematic viscosity $v$ makes up to $3 \%$. Investigation of the melt properties was performed using samples selected after melting at $1550{ }^{\circ} \mathrm{C}$ and cooling in a flat mould, as well as those in the form of a ribbon of an amorphous structure, which was produced from this alloy by rapid quenching from the melt.

A $25 \mu \mathrm{m}$ thick and $10 \mathrm{~mm}$ wide ribbon of an amorphous structure was produced by the planar flow casting process. The ribbon was wound up onto ring-type cores of the $32 \mathrm{~mm}$ outer diameter and $20 \mathrm{~mm}$ inner diameter. The cores were subjected to annealing at the given temperature of $550^{\circ} \mathrm{C}$. The thermomagnetic analysis was performed with the simultaneous recording of the temperature inside the core by a thermocouple and the inductance of the winding wound over the core. The initial permeability $\mu$ was calculated from the inductance measurements at $1 \mathrm{kHz}$. The parameters of the magnetic hysteresis loops were measured by means of point-by-point DC testing. The structural state of specimens was studied using transmission electron microscopy on a JEM 200CX microscope.

\section{Results and discussion}

It follows from the molecular-kinetic theory of viscosity that the dependence of kinematic viscosity $v$ on the absolute temperature of the melt $T$ can be expressed through the Arrhenius equation [8]

$$
v=v_{0} e^{\frac{-E_{a}}{R T}},
$$

where $v_{0}$ is the constant factor with the dimensionality of the kinematic viscosity $\mathrm{m}^{2} / \mathrm{s}, E_{a}$ is the energy of activation of the viscous flow $\mathrm{J} / \mathrm{mol}, R$ is the gas constant $\mathrm{J} / \mathrm{mol}$. After taking the logarithm of equation (1) we obtain

$$
\ln v=\ln v_{0}-\frac{E_{a}}{R T}
$$

Thus, the logarithm of the kinematic viscosity, $\ln v$, is a linear function of the inverse absolute temperature, $1 / T$.

Fig. 1 shows temperature dependences of the kinematic viscosity in the course of heating the sample of the $\mathrm{Fe}_{72.5} \mathrm{Cu}_{1} \mathrm{Nb}_{2} \mathrm{Mo}_{1.5} \mathrm{Si}_{14} \mathrm{~B}_{9}$ alloy subjected to cooling after melting at $1550{ }^{\circ} \mathrm{C}$ to cooling in a flat mould. Numerical values of the viscosity are shown on the normal logarithmic scale, whereas those of the absolute temperature are given on the inverse scale. The arrow shows the course of increasing the melt temperature. The curve of heating has two linear portions, which allows a numerical calculation of the energy of viscous flow $E_{a}$, which is equal for the initial portion of heating to $18 \mathrm{~kJ} / \mathrm{mol}$ and for a temperature above $1490{ }^{\circ} \mathrm{C}, 61 \mathrm{~kJ} / \mathrm{mol}$. 


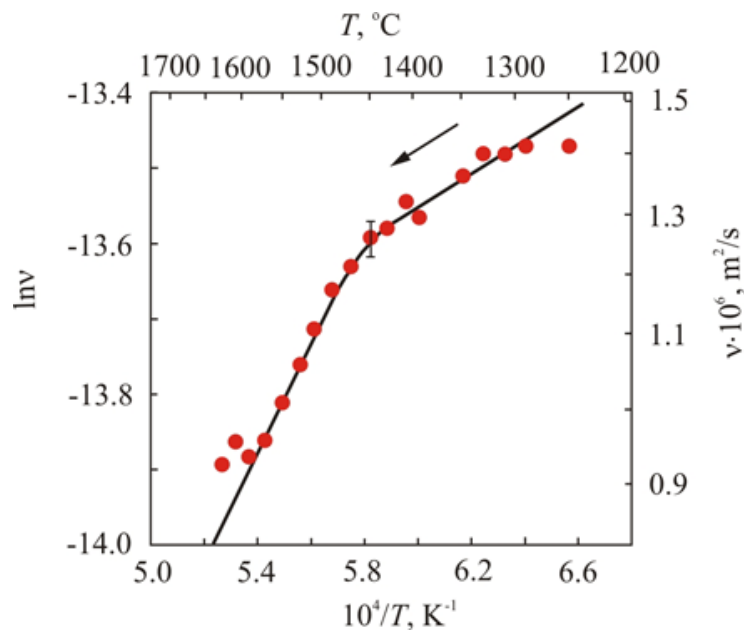

Fig. 1. Dependences of the logarithm of kinematic viscosity, $\ln v$, on the inverse absolute temperature, $1 / T$, in the course of heating of the sample of the $\mathrm{Fe}_{72.5} \mathrm{Cu}_{1} \mathrm{Nb}_{2} \mathrm{Mo}_{1.5} \mathrm{Si}_{14} \mathrm{~B}_{9}$ alloy subjected to cooling after melting in a flat mould.

Thus, upon heating the $\mathrm{Fe}_{72.5} \mathrm{Cu}_{1} \mathrm{Nb}_{2} \mathrm{Mo}_{1.5} \mathrm{Si}_{14} \mathrm{~B}_{9}$ melt above $1490{ }^{\circ} \mathrm{C}$, the viscous flow of the melt changes. These changes can be assigned to breaking interatomic bonds that control the short-range order in the melt [6]. The temperature of $1490{ }^{\circ} \mathrm{C}$ can be taken as a critical point $T_{k}$ for the $\mathrm{Fe}_{72.5} \mathrm{Cu}_{1} \mathrm{Nb}_{2} \mathrm{Mo}_{1.5} \mathrm{Si}_{14} \mathrm{~B}_{9}$ alloy above which the viscous flow of the melt changes by the Arrhenius law with another numerical value of the activation energy of the viscous flow $E_{a}$.

The results obtained indicate that for the multicomponent $\mathrm{Fe}_{72.5} \mathrm{Cu}_{1} \mathrm{Nb}_{2} \mathrm{Mo}_{1.5} \mathrm{Si}_{14} \mathrm{~B}_{9}$ melt, there is the critical temperature $T_{k}=1490{ }^{\circ} \mathrm{C}$ above which the melt can be converted into another structural state with a different magnitude of the activation energy of the viscous flow $E_{a}$. To compare two states of the melt, above and below the critical temperature, a ribbon of $25 \mu \mathrm{m}$ thick was cast from the melt prepared by two modes before the following ultrarapid cooling. In the first mode, the melt of $\mathrm{Fe}_{72.5} \mathrm{Cu}_{1} \mathrm{Nb}_{2} \mathrm{Mo}_{1.5} \mathrm{Si}_{14} \mathrm{~B}_{9}$ was heated up to $1480{ }^{\circ} \mathrm{C}$ before casting a ribbon. In the second mode, the melt of the same ingot was heated up to $1520{ }^{\circ} \mathrm{C}$, then cooled to $1480{ }^{\circ} \mathrm{C}$, and cast. At each temperature specified the exposure time was 5 min.

In Fig. 2, temperature dependences of kinematic viscosity are presented for the melts produced from the amorphous ribbons that were poured in melt preparation regimes 1 and 2 . The temperature of the melt was repeatedly changed from the minimal $T_{\min }=1200{ }^{\circ} \mathrm{C}$ to the maximal $T_{\max }$, which made up $1450{ }^{\circ} \mathrm{C}$ in the first cycle and $1600{ }^{\circ} \mathrm{C}$ in the second and third ones. At the very beginning of heating melts 1 and 2 from the amorphous ribbon, numerical values of the kinematic viscosity were virtually equal and made up $1.2 \cdot 10^{-6} \mathrm{~m}^{2} / \mathrm{s}$. However, on elevating the temperature, the viscosity of the melt produced from the ribbon prepared in the regime of overheating $\left(1520{ }^{\circ} \mathrm{C} \rightarrow 1480{ }^{\circ} \mathrm{C}\right.$, melt 1$)$ grows, unlike that without overheating $\left(1480{ }^{\circ} \mathrm{C}\right.$, melt 2$)$. After the second and third "heating-cooling" cycles, the temperature-versus-kinematic viscosity curves become stable; yet, the numerical value of viscosity for the melt undergone overheating is approximately twice as large as that for the regime without overheating. The temperature point corresponding to the change of the curve slope in Fig. 2 shifted to $1420{ }^{\circ} \mathrm{C}$ compared to $1490{ }^{\circ} \mathrm{C}$ for the initial ingot (Fig. 1), i.e. the change in the activation energy of the viscous flow in the melt produced from the amorphous ribbon takes place at a lower temperature. Note that the numerical values of the viscosity of the melt produced from the melt in the regime with overheating are close to the values for the melt prepared from the ingot immediately after casting and cooling the 
$\mathrm{Fe}_{72.5} \mathrm{Cu}_{1} \mathrm{Nb}_{2} \mathrm{Mo}_{1.5} \mathrm{Si}_{14} \mathrm{~B}_{9}$. The results obtained show that the viscosity of the melt essentially depends on the initial structural state.

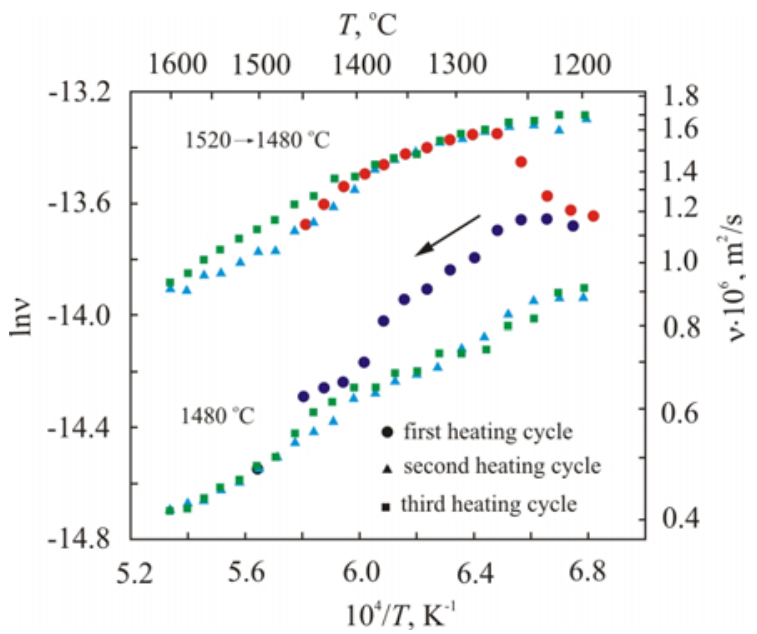

Fig. 2. Dependences of the logarithm of kinematic viscosity, $\ln v$, at on the inverse absolute temperature, $1 / T$, in the course of heating the samples of the amorphous ribbon which was produced in preparation regime 1 (heating to $1480^{\circ} \mathrm{C}$ before casting a ribbon) and 2 (heating to $1520^{\circ} \mathrm{C}$, then cooling to $1480^{\circ} \mathrm{C}$, and cast).

Investigation in the ribbon's amorphous structure in its initial state and after heat treatment, using transmission electron microscopy, showed that the ribbon's structure differed insignificantly in different regimes of melt preparation (Fig. 3 and 4).


Fig. 3. Bright-field images and micro-diffraction patterns for ribbon prepared by the regime without overheating $\left(1480{ }^{\circ} \mathrm{C}, 1-3\right)$ and with overheating $\left(1520{ }^{\circ} \mathrm{C} \rightarrow 1480{ }^{\circ} \mathrm{C}, 4-6\right)$ after heat treatment at $460(1,4), 480(2,5)$ and $550^{\circ} \mathrm{C},(3,6)$.

In accordance with micro-diffraction patterns, the structure of both samples is amorphous right up to the temperature of heat treatment of $460{ }^{\circ} \mathrm{C}$. The first crystallites appear at $480{ }^{\circ} \mathrm{C}$ and are of medium size of $3.5 \mathrm{~nm}$. In this case, for the preparation mode of 
$1520 \rightarrow 1480{ }^{\circ} \mathrm{C}$ (regime 2 ) the contribution of crystallites of $1-2 \mathrm{~nm}$ is greater than for the preparation mode of $1480{ }^{\circ} \mathrm{C}$ (regime 1). After heat treatment at $550{ }^{\circ} \mathrm{C}$, the crystallites' medium size was $8 \mathrm{~nm}$; in the process, the contribution of crystallites of $1-2 \mathrm{~nm}$ size was also greater for the preparation mode of $1520 \rightarrow 1480{ }^{\circ} \mathrm{C}$.

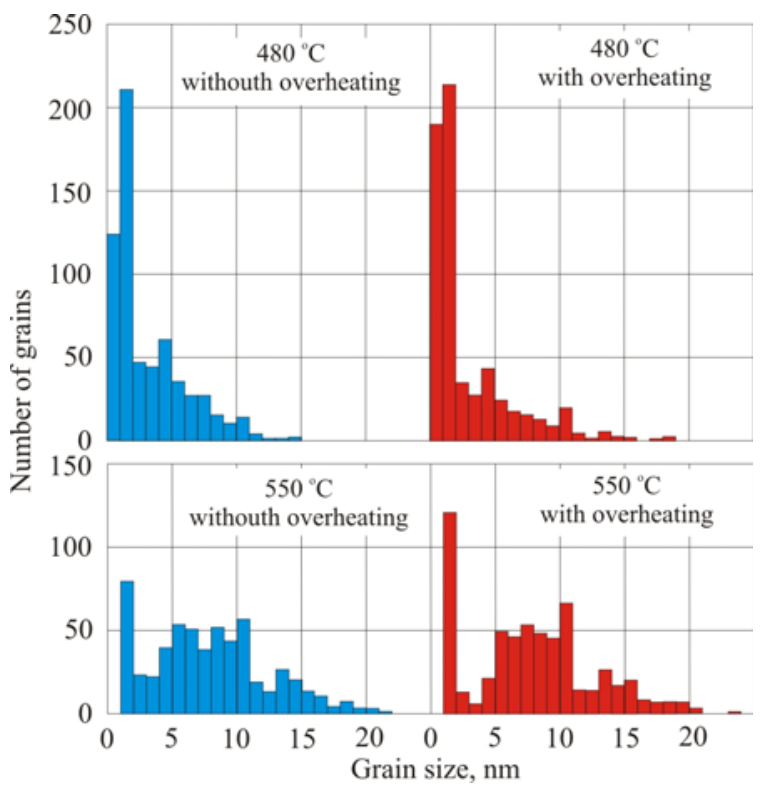

Fig. 4. Histograms of grain-size distributions in ribbon prepared by the regime without overheating $\left(1480{ }^{\circ} \mathrm{C}\right.$, cyan) and with overheating $\left(1520^{\circ} \mathrm{C} \rightarrow 1480{ }^{\circ} \mathrm{C}\right.$, red) after heat treatment at 480 and 550 ${ }^{\circ} \mathrm{C}$.

Figure 5 shows the in-time changes in the temperature and initial permeability in the course of heat treatment at $550{ }^{\circ} \mathrm{C}$ for the cores fabricated from the ribbons that were subjected to two modes of preparation of the $\mathrm{Fe}_{72.5} \mathrm{Cu}_{1} \mathrm{Nb}_{2} \mathrm{Mo}_{1.5} \mathrm{Si}_{14} \mathrm{~B}_{9}$ melt. From the temperature curve it is possible to determine the initial rate of heating of the core prior to crystallization $V_{0}$, the onset temperature of crystallization $T_{c r}$ (the staring point of the nonlinear growth of temperature), the maximal rate of heating the core $V_{m}$, and the peak temperature in the course of crystallization $T_{m}$. On the curve of magnetic permeability, it is possible to pick out the onset temperature of the fastest growth of permeability $T_{\mu}$, its peak value $\mu_{m}$, and stabilized value $\mu_{s t}$ after completion of the crystallization process. Numerical values of crystallization parameters of the $\mathrm{Fe}_{72.5} \mathrm{Cu}_{1} \mathrm{Nb}_{2} \mathrm{Mo}_{1.5} \mathrm{Si}_{14} \mathrm{~B}_{9}$ alloy for two modes of the melt preparation are given in Table 1.

Among the results presented, a special attention is to be paid to the enhanced rate of growing temperature in the course of crystallization $V_{m}=39^{\circ} \mathrm{C} / \mathrm{min}$ and peak temperature $T_{m}$ $=581{ }^{\circ} \mathrm{C}$ for the preparation mode $1520 \rightarrow 1480{ }^{\circ} \mathrm{C}$, which corresponds to a larger enthalpy of crystallization. All other conditions being equal, these data can evidence a higher degree of the structural disorder in the amorphous precursor obtained with overheating above the critical temperature. The more active the process of crystallization is, the higher the peak value of permeability $\mu_{m}$. What is of great interest is the time difference between peaks of heat release and permeability on the curves depicting the process dynamics, shown in Fig. 3 . The permeability peak appears just after the metal temperature is beginning to decrease. The formation of the amorphous-crystalline structure with nanocrystals implanted into the amorphous matrix is over after the peak temperature is reached. $\alpha$-FeSi-based nanocrystals have a lower content of silicon at the initial state of the crystallization process. This silicon 
content is gradually increasing up to $\alpha-\mathrm{Fe}_{80} \mathrm{Si}_{20}$ [9]. Nanocrystals can also contain Mo, the solubility of which is $2.5 \%$ in $\alpha-\mathrm{Fe}$ at $700{ }^{\circ} \mathrm{C}[10,11]$. The amorphous matrix permeability is close to $300{ }^{\circ} \mathrm{C}$. As the core permeability is beginning to grow at the stage of temperature decreasing, then the $\mu_{m}$ peak appearance can be attributed to the transition of nanocrystals from the paramagnetic state into the ferromagnetic one. On the other hand, after reaching the peak of crystallization, residual processes of the structure rearrangement and diffusion of components continue for several more minutes. Therefore, the permeability fall after reaching the peak value can be attributed to the transition of the atomic and magnetic structure into a stabilized state.

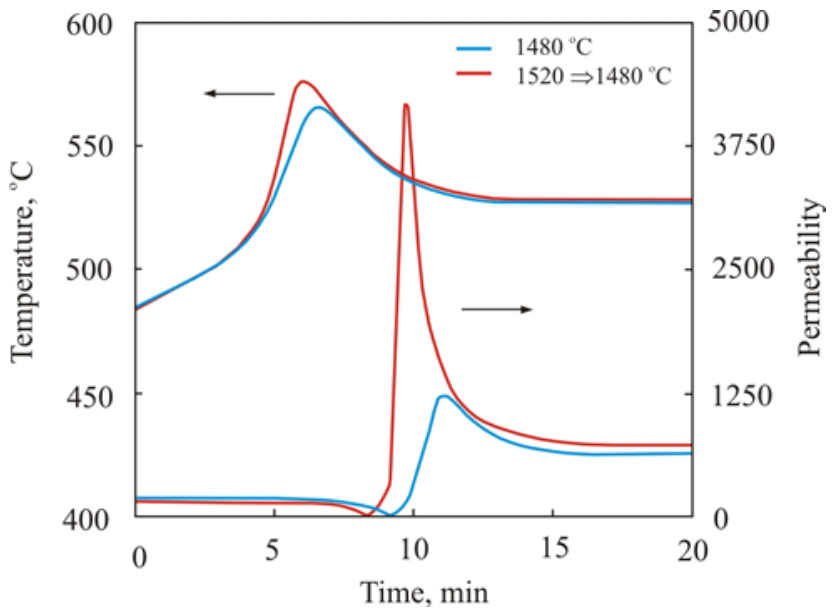

Fig. 5. Temperature and permeability changes in the course of heat treatment of cores made from the ribbons undergone preparation of the $\mathrm{Fe}_{72.5} \mathrm{Cu}_{1} \mathrm{Nb}_{2} \mathrm{Mo}_{1.5} \mathrm{Si}_{14} \mathrm{~B}_{9}$ melt by two modes.

Table 1. Parameters of crystallization of the $\mathrm{Fe}_{72.5} \mathrm{Cu}_{1} \mathrm{Nb}_{2} \mathrm{Mo}_{1.5} \mathrm{Si}_{14} \mathrm{~B}_{9}$ alloy

\begin{tabular}{lccccccc}
\hline $\begin{array}{l}\text { Regime of melt } \\
\text { preparation }\end{array}$ & $\begin{array}{c}V_{0}, \\
{ }^{\circ} \mathrm{C} / \mathrm{min}\end{array}$ & $\begin{array}{c}V_{m}, \\
{ }^{\circ} \mathrm{C} / \mathrm{min}\end{array}$ & $T_{c r},{ }^{\circ} \mathrm{C}$ & $T_{m},{ }^{\circ} \mathrm{C}$ & $T_{\mu},{ }^{\circ} \mathrm{C}$ & $\mu_{m}$ & $\mu_{s t}$ \\
\hline $1480{ }^{\circ} \mathrm{C}$ & 4.5 & 22 & 520 & 570 & 548 & 1270 & 650 \\
$1520 \rightarrow 1480{ }^{\circ} \mathrm{C}$ & 4.5 & 39 & 520 & 581 & 553 & 4300 & 760 \\
\hline
\end{tabular}

The cores fabricated from the ribbons obtained by two modes of the melt preparation were subjected together to the heat treatment at the temperature of $550{ }^{\circ} \mathrm{C}$ for $1 \mathrm{~h}$ after the crystallization peak is reached. In Table 2 , demonstrates the data on the permeability $\mu_{0.08}$ at the magnetic field strength of $0.08 \mathrm{~A} / \mathrm{m}$, maximal permeability $\mu_{\max }$, coercivity $H_{c}$ of the magnetic hysteresis loop at the maximal magnetic field strength of $800 \mathrm{~A} / \mathrm{m}$. It is seen that the mode with overheating of the melt above the critical temperature provides higher magnetic properties.

Table 2. Magnetic properties of cores made from the $\mathrm{Fe}_{72.5} \mathrm{Cu}_{1} \mathrm{Nb}_{2} \mathrm{Mo}_{1.5} \mathrm{Si}_{14} \mathrm{~B}_{9}$ alloy

\begin{tabular}{lccc}
\hline $\begin{array}{l}\text { Regime of melt } \\
\text { preparation }\end{array}$ & $\mu_{0.08}$ & $\mu_{\max }$ & $H_{c}, \mathrm{~A} / \mathrm{m}$ \\
\hline $1480{ }^{\circ} \mathrm{C}$ & 125000 & 882000 & 0.45 \\
$1520 \rightarrow 1480{ }^{\circ} \mathrm{C}$ & 164000 & 1024000 & 0.40 \\
\hline
\end{tabular}




\section{Summary}

In the work, the temperature dependences of the kinematic viscosity of the multicomponent $\mathrm{Fe}_{72.5} \mathrm{Cu}_{1} \mathrm{Nb}_{2} \mathrm{Mo}_{1.5} \mathrm{Si}_{14} \mathrm{~B}_{9}$ melt have been studied. The results of measurements were treated with the use of the Arrhenius law. The critical temperature is established above which the activation energy of the viscous flow of the melt changes. Comparison of the temperature dependences of the kinematic viscosity of the melts prepared from the initial ingot and an amorphous ribbon shows that the viscosity of the melt essentially depends on the initial structural state. In the amorphous ribbon obtained in the mode of the melt preparation with overheating above the critical temperature, an enhanced value of the crystallization enthalpy of is found. After the heat treatments of the cores, the mode with overheating the melt above the critical temperature results in higher magnetic properties.

\section{Acknowlegements}

This work was supported by the Scientific researches of higher education institutions within the State task of the Russian Federation No. 2014/236.

\section{References}

1. G. Herzer, Handbook of Magnetic Materials, edited by K.H.J. Buschow, 10, 415 (1997)

2. V.P. Manov, S.I. Popel, P.I. Buler, A.B. Manukhin, D.G. Komlev, Mater. Sci. Eng. A133, 535 (1991)

3. G. Kumar, T. Ohkubo, K. Hono, J. Mater. Res. 24, 2353 (2009)

4. P.S. Popel, V.E. Sidorov, Mater. Sci. Eng. A226-228, 237 (1997)

5. U. Dahlborg, M. Calvo-Dahlborg, P.S. Popel, V.E. Sidorov, Eur. Phys. J. B14, 639, (2000)

6. B.A. Baum, Metal liquids (Nauka, Moscow, 1979)

7. V. Tsepelev, V. Konashkov, Y. Starodubtsev, Y. Belozerov, D. Gaipisherov, IEEE Trans. Magn. 48, 1327 (2012)

8. J. Frenkel, Kinetic theory of liquids (Claredon Press, 1946)

9. K. Hono, D.H. Ping, M. Onhuma, H. Ondera, Acta Mater. 47, 997 (1999)

10. O. Kubaschewski, Iron - binary phase diagrams (Springer, 1982)

11. Diagrams of binary metallic systems, Vol. 2, Ed. N.P. Lyakishev (Moscow, 1997) 